\section{Cytochrom P450}

O. A. Gressner ${ }^{1}$ und A. M. Gressner ${ }^{2}$

${ }^{1}$ Labor Dr. Wisplinghoff Köln, Köln, Deutschland

${ }^{2}$ Labor Dr. Wisplinghoff Berlin, Berlin, Deutschland

\section{Synonym(e) CYP}

Englischer Begriff cytochrome p450

Definition Familie von Hämproteinen mit mischfunktioneller Monooxygenase-Aktivität.

Beschreibung Der erstmalige Nachweis eines CO-bindenden Pigments in Lebermikrosomen erfolgte durch M. Klingenberg 1958, welcher diesem aufgrund seines photometrischen Absorptionsmaximums bei $450 \mathrm{~nm}$ den Namen Cytochrom P450 (CYP) gab. Bei CYP handelt sich um eine Familie von Hämproteinen (MW 44-55 kDa) mit Oxidoreduktase-Aktivität, welche Eisen-Protoporphyrin IX als prosthetische Gruppe enthalten. Die häufigste durch CYP katalysierte Reaktion ist eine Monooxygenase-Reaktion, d. h. Insertion eines Sauerstoffatoms in ein organisches Substrat $(\mathrm{RH})$, während das andere Sauerstoffatom zu Wasser reduziert wird: $\mathrm{RH}+\mathrm{O}_{2}+2 \mathrm{H}^{+}+2 \mathrm{e}^{-} \rightarrow \mathrm{ROH}+\mathrm{H}_{2} \mathrm{O}$. Hierdurch wird die Löslichkeit des Substrats verbessert und somit seine Elimination gewährleistet (Biotransformation). Als solche sind CYP die wichtigsten Enzyme des Phase-I-Metabolismus zur hepatischen Detoxifikation.

CYP kommen ubiquitär in Bakterien, Pflanzen und Tieren vor und sind in der Phospholipidmatrix des endoplasmatischen Retikulums eukaryonter Zellen, mit höchster Dichte in den Hepatozyten der Leber, lokalisiert. Bisher sind mehr als 50 verschiedene CYP-Isoenzyme beim Menschen identifiziert worden, hierunter als wichtigste Vertreter CYP1A2, CYP2C9, CYP2D6 und vor allem CYP3A4 mit dem breitesten Substratspektrum. Das Isoenzymmuster zeigt eine zellspezifische Variabilität. Durch die Aufnahme spezifischer Fremdstoffe kann die Expression verschiedener Cytochrom-P450-Gene selektiv erhöht werden (Enzyminduktion). Die Folge ist eine verstärkte Biotransformation des (induzierenden) Fremdstoffs.

\section{Literatur}

Sigel R, Sigel A, Sigel H (2007) The ubiquitous roles of cytochrome P450 proteins: metal ions in life sciences. Wiley, New York 